\title{
Using Cloud Technologies for Engaging People with Cultural Heritage
}

\author{
Silvia de los Ríos, María Fernanda Cabrera-Umpiérrez, María Teresa Arredondo , \\ Patricia Abril , Viveca Jiménez, and Christos Giachritsis
}

\begin{abstract}
Cultural heritage is an important asset of Europe which is largely underexplored. One of the main reasons is that the general public do not really incorporate cultural activities in their life style. Currently, curators and professionals in the heritage sector face the toughest challenges on how to attract, engage and retain visitors of heritage institutions (libraries, museums, archives and historical societies). TAG CLOUD FP7 European project seeks to overcome this situation and promote lifelong engagement with culture by personalising the visitors' cultural experiences through cloud technologies.
\end{abstract}

Keywords: cultural heritage, cloud technologies, TAG CLOUD, engagement, personalisation.

\section{Introduction}

Nowadays, in Europe, although cultural heritage is an important value for the population, it is not sufficiently explored. People do not really incorporate cultural activities in their lifestyle, and thus, the engagement with culture is low. About $50 \%$ of the population does not visit any museum, has not been to a public library or has not visited any historical monument, and the participation in other cultural activities regularly is minor (about 38\%) [1]. Meanwhile, the current curators and professionals in the heritage sector are continually trying to capture and retain visitors.

Generally, they try to monitor how visitors interact with artefacts and sites during their visits and engage them on the basis of general information about their social and cultural background. For this purpose, a range of digital technologies from relatively cheap interactive websites to expensive on-site 3D visualisations are being used. However, these approaches have only limited success since they still follow the same "centralised" strategy of producing and delivering cultural content to the general public; that is, the content of the artefact and the characteristics of the visitors, which are used for "personalising" experiences, are still defined by the "experts". This means that, despite the employment of these technologies, the success of significantly increasing their visitors' base has been limited. 
Especially nowadays, with the framework of the economic crisis, culture promotion is at the hearts of the European policies. According to the European Commission President Jose Manuel Barroso "Culture and creativity touch the daily life of citizens. They are important drivers for personal development, social cohesion and economic growth. [...] Today's strategy promoting intercultural understanding confirms culture's place at the heart of our policies" [2]. Moreover, culture is an important economical resource. As it states the European Commission's Communication on "An integrated industrial policy for the globalisation era", "the cultural and creative industries are important drivers of economic and social innovation in other sectors" [3]. The Communication is accompanied by the annual European Competitiveness Report, which highlights that "creative industries are increasingly a source of growth in the EU", accounting for "3.3\% of total EU GDP and 3\% of employment" [4].

Taking into account this socioeconomic framework, promoting engagement with cultural heritage and active participation of the people with their cultural environment entails a great opportunity for social and economic development, at European and global level.

With this aim, and framed in the Call 8 "ICT for access to cultural resources" of the 7th Framework Programme of the EU, the European project TAG CLOUD [5] started on February 2013. TAG CLOUD, that means "Technologies lead to Adaptability \& lifelong enGagement with culture throughout the CLOUD", seeks to personalise cultural experiences for promoting lifelong engagement with culture through cloud technologies.

\section{Background}

In the last decade, the rapid growth on the Internet has benefited the initiatives for the transmission of cultural heritage [6]. About the $42 \%$ of all leisure-time users say that they use the Internet to obtain information on cultural events and products, and $73 \%$ of them use social networks [1]; their own experience and the experience of their community influence them on how and where to spend their leisure time. On the other hand, cultural institutions are gradually adopting new technologies for promoting culture, (some examples in Spain, augmented reality in some cities like Segovia [7] and Salamanca [8], Street Museum of London [9]...). However, still the number of museums and cultural institutions that use the Internet and social media for information purposes are low [6], and they do not incorporate innovative personalized uses of ICT or take into account the trends of the population to engage their visitors.

Technology has a big potential to fulfil the needs of cultural institutions and their visitors. From the desktop computers to smartphones, the cultural heritage institutions have gradually introduced technologies as tools to engage visitors. However, it offers a lot of opportunities that still do not have a high impact in culture:

- It provides new ways of interaction with the cultural environment.

- It allows personalisation of content according to the profile of the user. 
- It enables active participation in Culture.

- It allows collaboration between curators and professionals of the cultural sector with experts and end users.

In an attempt to incorporate technology into Culture several on-going and recently finalised projects from different European research areas have explored the field of adaptive cultural experiences, such as DECIPHER [10], CULTURA [11], CHESS [12], ARtSENSE [13] and PATHS [14]. Solutions proposed by these projects offer adaptive systems to assist the user during a cultural experience, online (CULTURA, PATHS) or in situ (DECIPHER, CHESS and ARtSENSE).

However there is still the need to achieve the cultural engagement thought a lifelong experience. A new approach is necessary that can facilitate private and public cultural institutions efforts to engage visitors, help them to reduce costs and increase the number of new visitors while ensuring that those that previously had visited them, continue their lifelong experience with the cultural institution. This approach should be based on collaboration between professionals in the heritage sector and ICT developers. It should address adaptive interaction and personalised content of existing artefacts and cultural heritage institutions through the involvement of the general public and professional users. In addition, this collaboration should take advantage of existing and widely available technologies in order reduce cost, access more people and increase profitability.

\section{The Concept}

TAG CLOUD aims to develop a new paradigm in adaptive cultural heritage engagement systems that enable the active involvement of the individuals in the creation of cultural content as a mechanism for truly personalized interaction between user and cultural objects through social media and mobile technologies.

The project has a consortium of ten partners, from five European countries: Spain, Germany, United Kingdom, Italy and Norway. Within the partners, three of them are the pilot sites where TAG CLOUD is being implemented and assessed. These are three cultural sites with different needs and represent three different cultural environments: a large building complex, The Monumental Complex of Alhambra of Granada and Generalife, in Granada (Spain); a museum, the Barber Institute of Fine Arts, in Birmingham (United Kingdom); and an open landscape, the County of Sør Trøndelag, in Norway.

TAG CLOUD offers a radically new approach in defining cultural content and creating personalised experiences with cultural heritage objects. TAG CLOUD uses cloud technologies to create context-aware artefacts where the context is being defined on the basis of information about the cultural background, habits and motives of individuals. TAG CLOUD harvests personal (non-sensitive) information from social media about individuals and fuse it with "expert" information about artefacts and sites in order to produce instances of cultural heritage objects that will appeal to and captivate individuals. Then, affordable cloud based technologies are used to attract and engage individuals with "their" cultural heritage objects. 


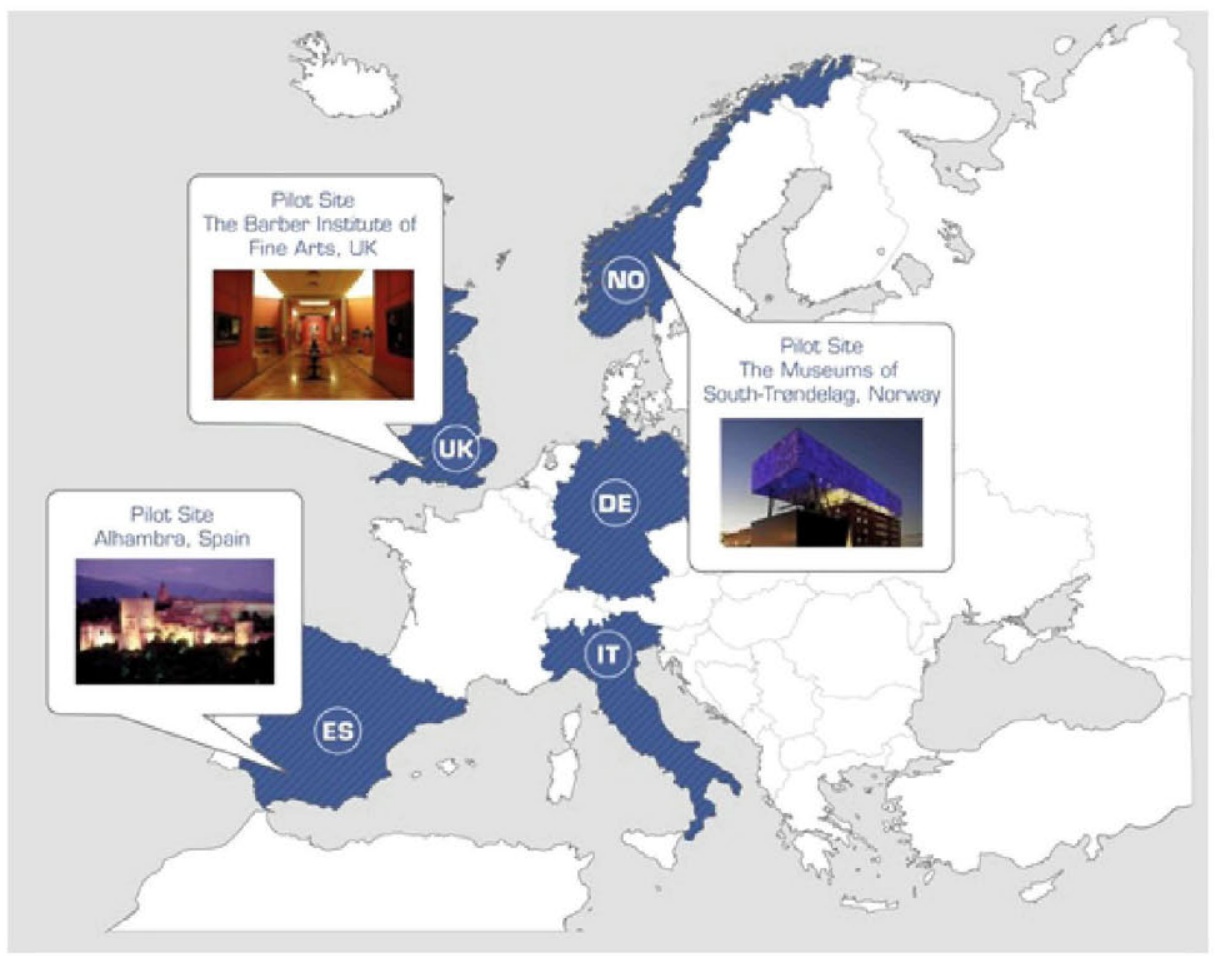

Fig. 1. TAG CLOUD consortium and pilots

The proposed TAG CLOUD system aims at increasing the active participation of general public in cultural events and experiences, by inviting to contribute with new content, opinions, as well as sharing their own experience with other people and heritage institutions, curators and researchers in the cultural area, before, during and after the visit. It is being designed to be dynamically personalized and adaptive to the needs, preferences and interests of the individuals and the community and is placed in the cloud, thus tapping the wide range of capabilities that cloud usage provides, allowing the availability of access from different locations in a secure fashion, as well as cost effective for both, individuals and cultural heritage institutions.

\section{The Methodology}

The TAG CLOUD system is based on a hybrid cloud, based on Software as a Service (SaaS) approach [15], composed by a public cloud which contains applications, tools and algorithms necessary to personalize the interaction between users and digital cultural artefacts, and several private clouds in which each heritage institution keeps its private digital cultural content, only available when the user is living a real cultural experience in such institution. In order to achieve this, TAG CLOUD adopts a multidisciplinary and multi-sector approach that includes cultural experts, curators, engineers and industrial partners with expertise in exploitation of cultural heritage and market research. 


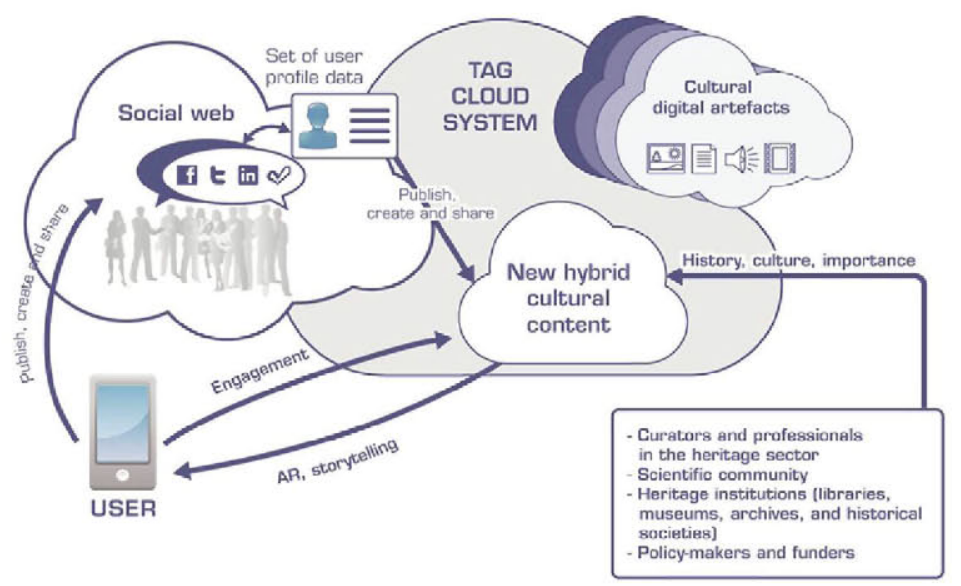

Fig. 2. TAG CLOUD system blocks diagram

TAG CLOUD (see Fig. 2) uses information from the public profile and contributions of the user in different social virtual networks and webs to acquire dynamic information about them (non-sensitive information) which is used to automatically update the static profile of the user (age, socio-cultural status, academic level, etc.) through the application of matching algorithms, and fuse it with information from experts about artefacts and cultural heritage places. The result of this fusion generates unique content for each user that is delivered through augmented reality or storytelling techniques creating new user's content that is used to dynamically adapt the experience.

TAG CLOUD explores the use of these technologies, like augmented reality, storytelling and social media, for a dynamic adaptation of cultural contents according to the visitors' profile, based on their preferences, likes and interests, providing a personalised interaction with culture. Through these technologies, the project encourages active participation in the creation of experiences and cultural content. The fusion of individuals' and experts' contents adds value and new meaning to the existing cultural artefacts, for promoting an effective communication between cultural institutions and final users towards the lifelong user engagement. Thus, TAG CLOUD offers a personalised cultural experience.

Based on this approach, TAG CLOUD aims to create a new relationship between individuals and cultural heritage, which will become part of the individual's life-style and will contribute to a lifelong cultural experience.

TAG CLOUD system design follows an iterative user centred approach that enables the users to be involved in all the phases of the project development. This iterative evaluation process enables on the one hand, the participation of the different stakeholders in the definition and design of TAG CLOUD system and on the other to test and validate the intermediate and final TAG CLOUD system prototype in different situations and domains. 
Within TAG CLOUD, there are two evaluation iterations scheduled, each of which will provide a thorough feedback of the perceived usefulness, ease of access and interaction, acceptance and satisfaction of the end users regarding the developments of the project. After the end of each evaluation round, the consolidated results will be provided to the development teams of the project for optimization in order to continue with the $2^{\text {nd }}$ round.

These two iterations are as follows:

- $1^{\text {st }}$ iteration: Lo/Me-Fi prototypes (stand-alone without adapted content) assessment (both qualitative and quantitative oriented evaluation incorporating a variety of techniques and tools).

- $2^{\text {nd }}$ iteration: Hi-Fi prototypes assessment (integrated).

The current plans for the iterative user testing to take place in TAG CLOUD are reflected in short in the following table:

Table 1. Pilots plans of TAG CLOUD

\begin{tabular}{|c|c|c|c|c|}
\hline \multirow[b]{2}{*}{$\begin{array}{l}\text { Iteration } \\
\text { cycle }\end{array}$} & \multirow[b]{2}{*}{$\begin{array}{l}\text { Prototype to be } \\
\text { tested }\end{array}$} & \multicolumn{3}{|c|}{ Pilot site/ number of users } \\
\hline & & Spain & Norway & $\begin{array}{r}\text { United } \\
\text { Kingdom }\end{array}$ \\
\hline $\begin{array}{c}1^{\text {st }} \\
\text { iteration }\end{array}$ & 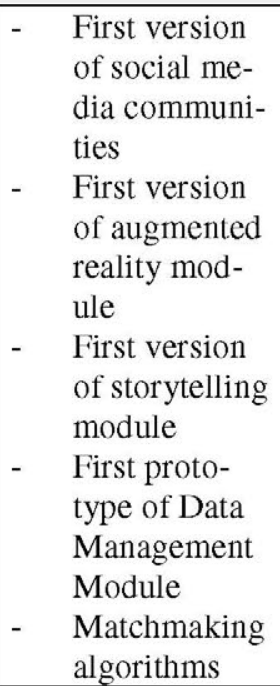 & $\begin{array}{l}\text { - } 15 \text { benefi- } \\
\text { ciaries of } \\
\text { various } \\
\text { groups } \\
\text { - } 3 \text { profes- } \\
\text { sionals in } \\
\text { cultural } \\
\text { heritage }\end{array}$ & $\begin{array}{l}\text { - } 15 \text { benefi- } \\
\text { ciaries of } \\
\text { various } \\
\text { groups } \\
\text { - } 3 \text { profes- } \\
\text { sionals in } \\
\text { cultural } \\
\text { heritage }\end{array}$ & $\begin{array}{l}\text { - } 15 \text { benefi- } \\
\text { ciaries of } \\
\text { various } \\
\text { groups } \\
-3 \text { profes- } \\
\text { sionals in } \\
\text { cultural } \\
\text { heritage }\end{array}$ \\
\hline $\begin{array}{c}2^{\text {nd }} \\
\text { iteration }\end{array}$ & $\begin{array}{l}\text { All WP2 and } \\
3 \text { applications }\end{array}$ & $\begin{array}{l}\text { - } 30 \text { benefi- } \\
\text { ciaries of } \\
\text { various } \\
\text { groups } \\
\text { - } 5 \text { profes- } \\
\text { sionals in } \\
\text { cultural } \\
\text { heritage }\end{array}$ & $\begin{array}{l}\text { - } 30 \text { benefi- } \\
\text { ciaries of } \\
\text { various } \\
\text { groups } \\
\text { - } 5 \text { profes- } \\
\text { sionals in } \\
\text { cultural } \\
\text { heritage }\end{array}$ & $\begin{array}{l}\text { - } 30 \text { benefi- } \\
\text { ciaries of } \\
\text { various } \\
\text { groups } \\
\text { - } 5 \text { profes- } \\
\text { sionals in } \\
\text { cultural } \\
\text { heritage }\end{array}$ \\
\hline
\end{tabular}


End users and experts will be selected and recruited to represent the range of stakeholders in a balanced way. For end users who are not adult, the process will be performed in close co-operation with families as well as with schools, etc. that we will be depending on to perform user evaluation and testing. The ethical issues will be assessed and taken into account throughout the whole recruitment and evaluation process.

The selection criteria for the end users include, among others:

- willingness to participate in the TAG CLOUD requirements' selection and testing activities,

- sex - if possible, $50 \%$ man and $50 \%$ women in each group,

- age - different age groups to ensure a spread across the population,

- previous experience of participation in similar activities of past or ongoing projects. This last criterion will be a huge benefit in terms of reducing the steepness of the user learning curve and bringing previous end user experiences (both good and bad) to the table and up to speed. It will also have the effect of avoiding some of the potential pitfalls that sometimes occur during iterative, heuristic evaluation processes.

\section{Conclusions}

TAG CLOUD offers a radically new approach in developing truly personalised cultural experiences to engage people with cultural heritage. The project seamlessly incorporates cloud-based (non-sensitive) information about the habits, preferences and motives of individuals into the digital content of a cultural object (e.g. artefacts, buildings, sites, etc.) and allows personalising the cultural experience. It will increase the users' interest for cultural heritage by making them active participants in the assignment of the 'importance' of a cultural artefact; thus they become actors in the creation of their own cultural experiences, creating, sharing, and adding information within social media. TAG CLOUD plans to add new meaning to cultural digital content by producing adaptive cultural contents based on fusion of expert and visitor information.

The methodology and interactive technologies that are being developed in TAG CLOUD will result in introducing more people into cultural heritage activities, improving the quality of their engagement and increasing the frequency of their visits to cultural sites.

At this point, after assessing the user needs and expectations through interviews and focus groups, the main scenarios and use cases that define the whole functionality of the system have been developed. First demonstration prototypes have been implemented and tested in the pilot sites at the early-stage evaluations of the project.

Acknowledgements. This work has been partially funded by the EC FP7 project TAG CLOUD (Technologies lead to Adaptability \& lifelong enGagement with culture throughout the CLOUD); http://www.tagcloudproject.eu/, Grant Agreement No. 600924. 


\section{References}

1. "Eurobarometer 67.1" (2007), http://ec.europa.eu/culture/pdf/doc958_ en .pdf (accessed October 14, 2013)

2. European Commission, Press Releases of the European Commission (2007), http: / /europa.eu/rapid/press-release_IP-07-646_en.htm (accessed October 14, 2013)

3. European Commission, An integrated industrial policy for the globalisation era (2010), http://ec.europa.eu/enterprise/policies/

industrial-competitiveness/industrial-policy/files/

communication_on_industrial_policy_en.pdf (accessed October 14, 2013)

4. European Commission, European Competitiveness Report (2010),

http://ec.europa.eu/enterprise/policies/industrial-

competitiveness/competitiveness-analysis/

european-competitiveness-report/index_en.htm (accessed October 14, 2013)

5. TAG CLOUD project, CN. 600924, 7th Framework Programme, ICT for access to cultural resources (February 2013), http: //www. tagcloudproject. eu/

6. EGMUS "European Group on Museum Statistics", http://www. egmus.eu/ index . php? id=88\&L=\&STIL= (accessed October 14, 2013)

7. Augmented Reality App for Segovia, Spain,

http://www.turismodesegovia.com/es/noticias/

noticias-actuales/232-varios/481-descargate

-la-guia-de-realidad-aumentada-de-segovia (accessed February7, 2013)

8. Augmented Reality App for Salamanca, Spain, http://www.salamanca.es/es/node/701 (accessed February7, 2013)

9. Street Museum of London App, http://www.museumoflondon.org.uk/ Resources/app/you-are-here-app/home.html (accessed February7, 2013)

10. DECIPHER project, CN. 270001, 7th Framework Programme, ICT-2009.4.1 Digital Libraries and Digital Preservation (January 2011), http : / decipher-research .eu/

11. CULTURA project, CN. 269973, 7th Framework Programme, ICT-2009.4.1 Digital Libraries and Digital Preservation (February 2011), http: / /www . cultura-strep .eu/

12. CHESS project, CN. 270198, 7th Framework Programme, ICT-2009.4.1 Digital Libraries and Digital Preservation (February 2011), http: / www . chessexperience . eu/

13. ARtSENSE project, CN. 270318, 7th Framework Programme, ICT-2009.4.1 Digital Libraries and Digital Preservation (February 2011), http://www. artsense. eu /

14. PATHS project, CN. 270082, 7th Framework Programme, ICT-2009.4.1 Digital Libraries and Digital Preservation (January 2011), http://paths-project.eu/

15. Verma, G.: Software as a Service. Pragyaan: Journal of Information Technology 9(1), 32-37 (2011) 